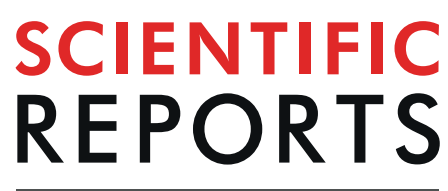

natureresearch

\title{
Effects of non-solvents and electrolytes on the formation and properties of cellulose I filaments
}

\author{
Ling Wang ${ }^{1}$, Meri J. Lundahl $\mathbb{D}^{1}$, Luiz G. Greca ${ }^{1}$, Anastassios C. Papageorgiou $\mathbb{D}^{2}$, \\ Maryam Borghei ${ }^{1}$ \& Orlando J. Rojas $\mathbb{( i b}^{1,3^{*}}$
}

Coagulation is a critical process in the assembly of cellulose nanofibrils into filaments by wet spinning; however, so far, the role of the coagulation solvent has not been systematically elucidated in this context. This work considers organic non-solvents (ethanol, acetone) and aqueous electrolyte solutions $\left(\mathrm{NaCl}(\mathrm{aq}), \mathrm{HCl}(\mathrm{aq}), \mathrm{CaCl}_{2}(\mathrm{aq})\right)$ for the coagulation of negatively charged cellulose nanofibrils via wet spinning. The associated mechanisms of coagulation with such non-solvents resulted in different spinnability, coagulation and drying time. The properties of the achieved filaments varied depending strongly on the coagulant used: filaments obtained from electrolytes (using $\mathrm{Ca}^{2+}$ and $\mathrm{H}^{+}$as counterions) demonstrated better water/moisture stability and thermomechanical properties. In contrast, the filaments formed from organic non-solvents (with $\mathrm{Na}^{+}$as counterions) showed high moisture sorption and low hornification when subjected to cycles of high and low humidity (dynamic vapor sorption experiments) and swelled extensively upon immersion in water. Our observations highlight the critical role of counter-ions and non-solvents in filament formation and performance. Some of the fundamental aspects are further revealed by using quartz crystal microgravimetry with model films of nanocelluloses subjected to the respective solvent exchange.

Assembling cellulose nanofibrils (CNF) into one-dimensional filaments has received increased attention, owing to the possibility to fully utilize the mechanical strength of the CNF through their alignment along the filament axis $^{1-11}$. Wet spinning has been generally applied, transforming the aqueous CNF suspension to filaments by extrusion through a spinneret into a coagulation bath ${ }^{1,4,12}$. Several factors influence the filament formation and its properties, such as dope formulation ${ }^{13-17}$, shear rate si, $^{18}$, and drawing ratio ${ }^{13,20,21}$.

The type of coagulation agent, bath concentration and temperature play important roles on filaments spun from cellulose and their characteristics, such as morphology, mechanical and viscoelastic properties ${ }^{22-24}$. We have previously observed that coagulation with $\mathrm{CaCl}_{2}$ solution facilitated wet spinning of lignin-based dopes (lignin/ TEMPO-oxidized CNF (TOCNF), 70:30), while acetone was not effective ${ }^{25}$. Therefore, in this study, we investigated the influence of the coagulation system on the wet-spinning of TOCNF and the final properties of the spun filaments. This is a subject that has not been addressed systemically in such contexts.

Coagulation is applied in film formation (wet-casting) and fiber spinning (dry-jet or wet- spinning), where phase separation of a polymer solution occurs in the bath by mass transport and exchange between the solvent and non-solvent ${ }^{26,27}$. During solvent exchange, counter-diffusion occurs according to Fick's law ${ }^{24}$. Thus, a polymer solution gradually loses its solvent, leading to decreased solubility ${ }^{28}$. In the case of the coagulation of a colloidal system such as CNF or TOCNF, instability and further phase-separation occur in the coagulation bath by the effect of interfibrillar aggregation. Two types of coagulation agents have been applied in wet-spinning of CNF, including organic solvents (such as ethanol, acetone, and tetrahydrofuran) as well as aqueous electrolytes $\left(\mathrm{CaCl}_{2}\right.$, $\mathrm{HCl})$. The organic solvents have to be miscible with water and with moderate polarity to facilitate hydrogen bonding between the fibrils ${ }^{15}$.

Aqueous electrolytes facilitate CNF coagulation through gelation by ion exchange $e^{5,9,20,21,25}$. The electrolyte type and concentration influence the surface charge, interaction energy and the dissociation of fibrils, consequently affecting the interfibrillar aggregation ${ }^{29-32}$. Moreover, the electrolytes species can displace the counterions in the

${ }^{1}$ Department of Bioproducts and Biosystems, School of Chemical Engineering, Aalto University, P.O. Box 16300, 00076, Aalto, Finland. ' $T u r k u$ Centre for Biotechnology, University of Turku and Åbo Akademi University, 20520, Turku, Finland. ${ }^{3}$ Departments of Chemical \& Biological Engineering, Chemistry and, Wood Science, 2360 East Mall, The University of British Columbia, Vancouver, BC, V6T 1Z3, Canada. *email: orlando.rojas@aalto.fi 


\begin{tabular}{|l|l|l|l|l|}
\hline Spinning bath & $\begin{array}{l}\text { Coagulation } \\
\text { time (s) }\end{array}$ & Washing & $\begin{array}{l}\text { Drying time } \\
\text { (min) }\end{array}$ & $\begin{array}{l}\text { Continuous } \\
\text { spinnability }\end{array}$ \\
\hline Ethanol & $\geq 30$ & No & $\geq 12$ & No \\
\hline Acetone & $\geq 5$ & No & $\geq 10$ & No \\
\hline $\mathrm{NaCl}(1 \mathrm{M})$ & immediately & No & $\geq 28$ & No \\
\hline $\mathrm{CaCl}_{2}(1 \mathrm{M})$ & immediately & Yes & $\geq 15 \mathrm{~min}$ & Yes \\
\hline $\mathrm{HCl}(\mathrm{pH} 2)$ & immediately & Yes & $\geq 30 \mathrm{~min}$ & Yes \\
\hline
\end{tabular}

Table 1. Effect of different coagulants on wet spinning. Note: In the case of $\mathrm{NaCl}$ electrolyte solution, $\mathrm{NaCl}$ salt precipitates on the surface of the filament. The coagulation time was estimated as the time from extrusion until filaments with a $15 \mathrm{~cm}$ in length were picked up from coagulation bath. 'Immediately' in the case of coagulation with electrolytes, is meant to indicate that such phenomenon occurred upon contact with the coagulation batch.

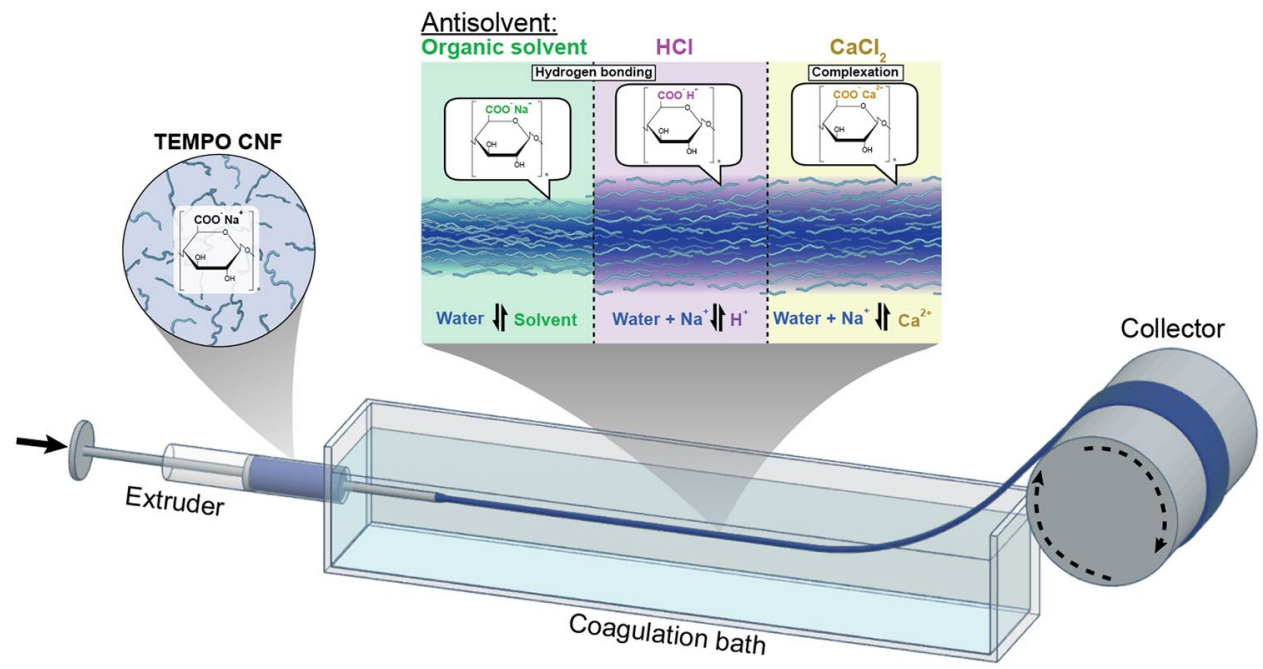

Figure 1. Schematic illustration from wet spinning system of aqueous suspensions of TOCNF using different spinning baths, leading to different mechanisms for filament formation.

charged groups (such as carboxylate), thus remarkably affecting the properties of the wet-spun filaments. So far, the effect of counterions has considered mainly aqueous dispersions for film casting. It was reported that the salt concentration, valence and size of the cations has a significant influence on the negatively charged CNF suspension (stability ${ }^{33-35}$, fibril orientation ${ }^{36}$ ) and the resultant film properties, such as water redispersibilty, mechanical performance, oxygen barrier performance and thermal stability ${ }^{29,31,36-39}$.

In this work, we systematically investigated the influence of coagulation agent (organic solvents and aqueous electrolytes) on the spinnability of TOCNF suspensions, considering the coagulation and drying times. The coagulation mechanism was studied by modelling the coagulation process through quartz crystal microgravimetry (QCM). The impact of the coagulation on ensuing filament properties was determined by characterization of the filament morphology, fibril orientation, mechanical properties, thermal stability as well as water stability and moisture sorption. Accordingly, compared to the filaments coagulated in organic solvents, those produced from aqueous electrolytes demonstrated more circular cross-section, better water/moisture stability and thermomechanical performance.

\section{Results and Discussion}

Impact of coagulant on wet spinning of TOCNF. TOCNF suspensions were wet spun in a spinning bath containing $400 \mathrm{ml}$ of either ethanol, acetone or aqueous solutions containing $\mathrm{NaCl}, \mathrm{CaCl}_{2}$ or $\mathrm{HCl}$. The effects of the medium on filament formation, coagulation and drying time, washing and continuous spinnability are listed in Table 1. It took some time to coagulate TOCNF in the organic non-solvents (acetone and ethanol). After extruding TOCNF in the coagulation bath, as shown in Fig. 1, the freshly formed hydrogel thread underwent counter-diffusion between water in the TOCNF suspension and the organic coagulant (ethanol, Et or acetone, Ac). As such, TOCNF gradually lost water and coagulated. It is reasonable to assume that due to the low affinity with ethanol and acetone, a dense semi-solidified shell formed via interfibrillar aggregation, which proceeded into the core, leading to the densification of the filaments (herein, referred to as $\mathrm{F}_{\mathrm{Et}}, \mathrm{F}_{\mathrm{Ac}}$ ), as discussed previously ${ }^{15,22}$. Because of the increased density, the filaments settled in the bottom of the coagulation bath. Since water diffuses faster in acetone (differential diffusion coefficient $5.22 \times 105 \mathrm{~cm}^{2} \mathrm{~s}^{-1}$ ) than in ethanol $\left(1.222 \times 105 \mathrm{~cm}^{2} \mathrm{~s}^{-1}\right)^{40}, \mathrm{~F}_{\mathrm{Ac}}$ was expected to coagulate faster than $\mathrm{F}_{\mathrm{Et}}(\sim 5 \mathrm{~s}$ and $30 \mathrm{~s}$, respectively). The original TOCNF was in the CNF$\mathrm{COO}^{-} \mathrm{Na}^{+}$form, which was confirmed by EDX (see sodium peak in the spectrum, Fig. S1a). In this process, the 
(a)

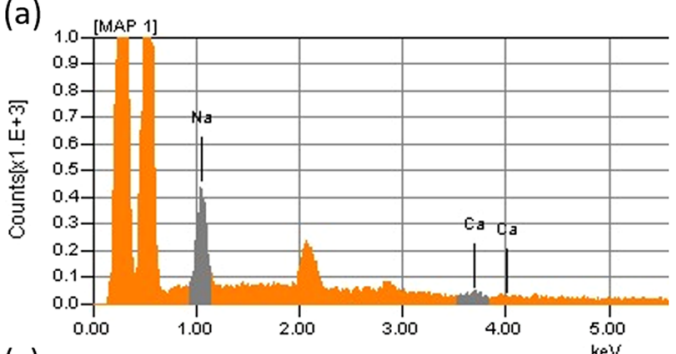

(c)

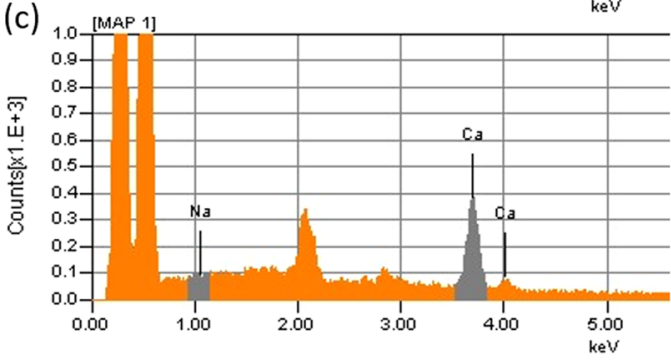

(b)

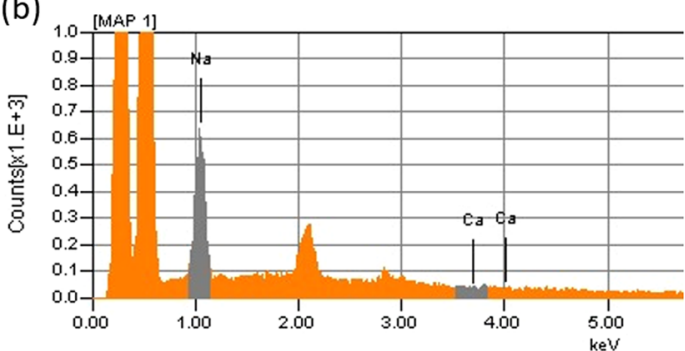

(d)

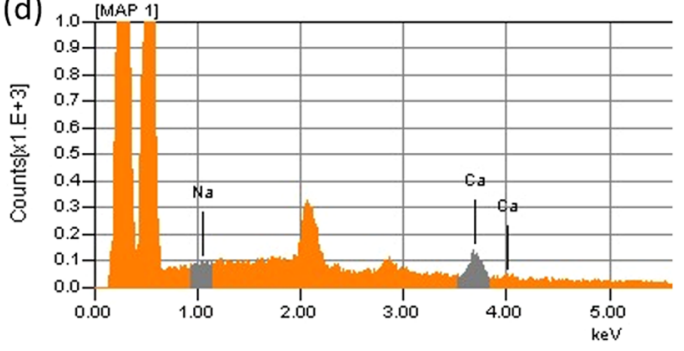

Figure 2. EDX spectra of the wet-spun filaments produced using different coagulants: $(\mathbf{a}) \mathrm{F}_{\mathrm{Et}},(\mathbf{b}) \mathrm{F}_{\mathrm{Ac}},(\mathbf{c}) \mathrm{F}_{\mathrm{Ca}}$ and $(\mathbf{d}) \mathrm{F}_{\mathrm{HCl}}$. Note: The presence of $\mathrm{Ca}$ in $(\mathbf{d})$ is due to cross contamination from the tweezers used with the other systems.

cellulose fibrils remained in the $\mathrm{CNF}-\mathrm{COO}^{-} \mathrm{Na}^{+}$form, Fig. 2a,b, indicating large amounts of sodium in both filaments, $\mathrm{F}_{\mathrm{Et}}$ and $\mathrm{F}_{\mathrm{Ac}}$.

Unlike the case of organic coagulants, filaments could be collected immediately from aqueous $\mathrm{NaCl}, \mathrm{HCl}$ and $\mathrm{CaCl}_{2}$ in which a dispersion-gelation transition occurred through ion diffusion ${ }^{15}$. In contrast, upon gelation, $\mathrm{F}_{\mathrm{Et}}$ and $\mathrm{F}_{\mathrm{Ac}}$ filaments tended to move to the surface of the coagulation bath. When TOCNF suspension was extruded in $\mathrm{HCl}$ solution at $\mathrm{pH} 2$, the carboxylate groups of TOCNF became protonated (Fig. 2) ${ }^{5,9}$. This reduced the fibril surface charge and electrostatic repulsion, and lowered the interaction potential between cellulose nanofibrils, according to the Derjaguin-Landau-Verwey-Overbeek theory (DLVO) ${ }^{29}$, leading to fibril aggregation and gela$\operatorname{tion}^{33}$. Since protons are not detectable by EDX, the reduced sodium peak in Fig. $2 \mathrm{~d}$ indicates that the majority of carboxylate groups in $\mathrm{F}_{\mathrm{HCl}}$ became protonated, i.e., in the $\mathrm{CNF}-\mathrm{COO}^{-} \mathrm{H}^{+}$form.

Several authors have shown that adding salt to CNF or CNC suspensions leads to fibril aggregation and partial gelation $^{29,30,32,38}$. The effects of salt screening, condensation and specific interactions between counterions and $\mathrm{COO}^{-}$reduce the TOCNF surface charge and further decrease the fibril interaction potential energy (DLVO), resulting in fibril aggregation. The salt concentration as well as valence play an important role in fibril aggregation. Accordingly, $1 \mathrm{M} \mathrm{NaCl}_{(\mathrm{aq})}$ and $\mathrm{CaCl}_{2(\mathrm{aq})}$ solutions were used as coagulants for wet spinning of TOCNF. Filaments could be immediately collected from both coagulants, though the $\mathrm{NaCl}_{(\mathrm{aq})}$ led to shorter filaments than those obtained from the $\mathrm{CaCl}_{2(\mathrm{ag})}$. This observation is explained by the weaker gel that does not support its weight when lifted from the coagulation. Upon drying, the filaments obtained from the $\mathrm{NaCl}_{(\mathrm{aq})}$ bath were covered with $\mathrm{NaCl}$ crystals. After placing the filaments in water, used to wash out the salt crystals, the filaments swelled significantly and became too weak to be picked up. Thus, no filaments could eventually be collected from $\mathrm{NaCl}_{(\mathrm{aq})}$.

According to Schultz-Hardy rule, the critical aggregation concentration of nanocellulose is related inversely with the valence of the cation in the electrolyte ${ }^{32}$. Thus, $\mathrm{CaCl}_{2(\mathrm{aq})}$ (that is, $\mathrm{Ca}^{2+}$ ) was applied as coagulant for TOCNF, inducing interfibrillar interactions by counterion condensation (Fig. 1) ${ }^{21,25}$. Calcium cations diffuse in the TOCNF dispersion and replace $\mathrm{Na}^{+38}$, leading to ionic bond formation between the negatively charged carboxylic groups and $\mathrm{Ca}^{+}\left(\mathrm{CNF}-\mathrm{COO}^{-}-\mathrm{Ca}^{2+}-{ }^{-} \mathrm{OOC}-\mathrm{CNF}\right)$. The enrichment in calcium and depletion of sodium (EDX spectrum, Fig. 2c), observed for $\mathrm{F}_{\mathrm{Ca}}$, can be taken as evidence that $\mathrm{Ca}^{2+}$ was exchanged with $\mathrm{Na}^{+}$in the coagulation bath. We note that there was some residual chloride in $\mathrm{F}_{\mathrm{Ca}}$ (Fig. S1b), indicating the possible presence of residual $\mathrm{CaCl}_{2}$ or other forms, such as $\mathrm{CNF}-\mathrm{COO}^{-} \mathrm{Ca}^{2+} \mathrm{Cl}^{-}$exists ${ }^{31,38}$. In general, to achieve filaments from TOCNF, fibril aggregation needs to occur in the coagulation bath, either by physical aggregation (organic solvent and $\mathrm{HCl}(\mathrm{aq}))$ or by chemical complexation $\left(\mathrm{CaCl}_{2}(\mathrm{aq})\right)$.

The time needed for the filaments to dry mainly depended on the evaporation rate of the coagulant used for filament formation. Hence, the semi-solidified filaments obtained from ethanol and acetone $\left(\mathrm{F}_{\mathrm{Et}}, \mathrm{F}_{\mathrm{Ac}}\right)$ dried much faster than those that were gellified in the electrolyte solution $\left(\mathrm{F}_{\mathrm{HCl}}\right.$ and $\left.\mathrm{F}_{\mathrm{Ca}}\right)$. An approximated similar drying rate, which was assessed qualitatively, was observed for $\mathrm{F}_{\mathrm{Et}}, \mathrm{F}_{\mathrm{Ac}}$ (around 10 min). Interestingly, the gel-like $\mathrm{F}_{\mathrm{Ca}}$ could not be dried in an ambient atmosphere due to the hygroscopicity of residual $\mathrm{CaCl}_{2}{ }^{41}$. As such, washing (by dipping the filaments in fresh water using 4 cycles and then immersion in water for $10 \mathrm{~min}$ and $2 \mathrm{~h}$, respectively) was necessary to remove the excess salts from $\mathrm{F}_{\mathrm{Ca}}$ filaments, followed by drying for $15 \mathrm{~min}$. Remarkably, it took much longer time for $\mathrm{F}_{\mathrm{HCI}}$ to dry $(30 \mathrm{~min})$, probably due to the ability of the carbonyl $(\mathrm{COOH})$ groups of TOCNF to form hydrogen bonds with water ${ }^{33}$. Overall, gel-like filaments obtained from chemical complexation $\left(\mathrm{F}_{\mathrm{Ca}}\right.$ and $\left.\mathrm{F}_{\mathrm{HCl}}\right)$ took longer time to dry than those obtained by physical aggregation/coagulation $\left(\mathrm{F}_{\mathrm{Ac}}\right.$ and $\left.\mathrm{F}_{\mathrm{Et}}\right)$. In practice, this indicates a trade-off between coagulation and drying times, as the solvents that undergo fast evaporation coagulated at slower rates. 

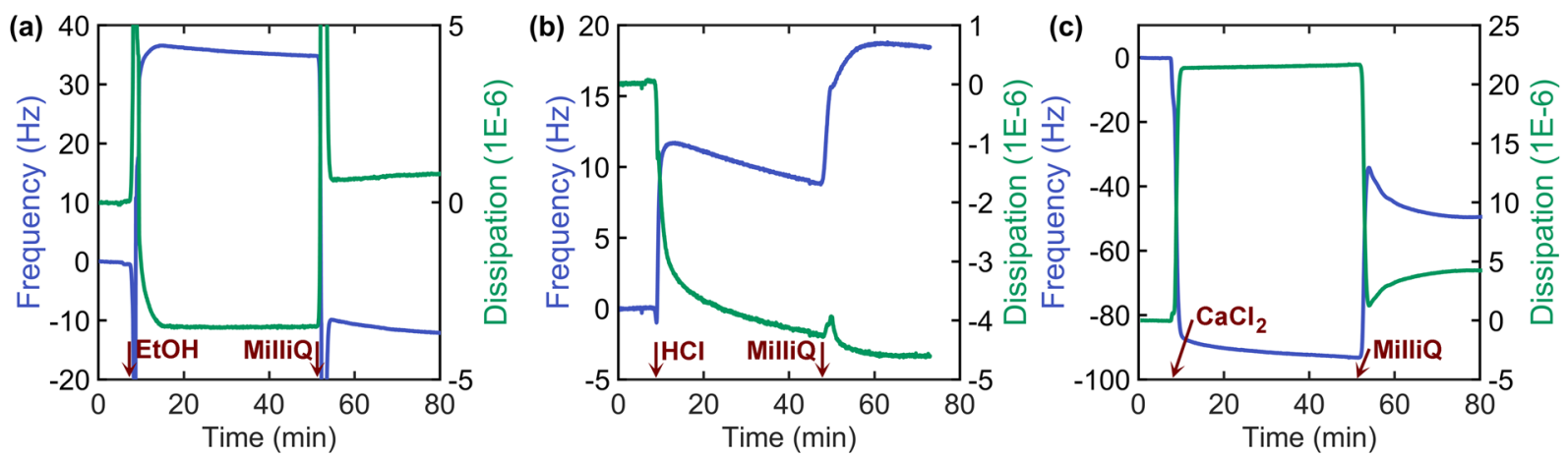

Figure 3. Frequency and dissipation of TOCNF-coated QCM-D crystals as a function of time upon contact with (a) $\mathrm{EtOH}$ ( $7^{\text {th }}$ overtone), (b) $\mathrm{HCl}_{(\mathrm{aq})}\left(3^{\text {rd }}\right.$ overtone), and (c) $\mathrm{CaCl}_{2(\mathrm{aq})}\left(7^{\text {th }}\right.$ overtone). Note: interference from bubbles is observed in the signals in (a), at the beginning of solvent exchange. In the time axis, the introduction of the respective solution and rinsing with MilliQ water are indicated.

In order to increase the spinning rate, and for the purpose of filament collection, continuous spinning was performed with the help of a winder. Even though a semi-solid structure was formed in the coagulation bath, the $\mathrm{F}_{\mathrm{Et}}$ and $\mathrm{F}_{\mathrm{Ac}}$ filaments were difficult to handle in the continuous spinning line. In contrast, continuous spinning into gel-like $\mathrm{F}_{\mathrm{Ca}}$ and $\mathrm{F}_{\mathrm{HCl}}$ was successfully achieved owing to strong interfibrillar interactions. Similar results have been reported by Hagström et al. and Kafy et al. who used $\mathrm{HCl}$ and $\mathrm{CaCl}_{2}$ as coagulants for continuous spinning of TOCNF 9 .

Coagulation mechanism as revealed by QCM-D. In order to further understand the mechanisms involved in TOCNF coagulation, model films of TOCNF were placed in a QCM-D unit and immersed in ethanol and aqueous electrolyte solutions $\left(\mathrm{CaCl}_{2}\right.$ and $\left.\mathrm{HCl}\right)$. The films were fixed on a solid support pre-coated with polyethyleneimine. Thus, TOCNF fibrils were attached to the surface while, assumedly, still remaining subjected to swelling. The shift over time of the QCM frequency and dissipation are presented in Fig. 3. The Voigt viscoelastic model was used to follow the changes in mass, noting that this should be taken as an attempt to quantitatively describe the complex phenomena involved in the spinning process (see Fig. S2).

After introducing ethanol, the frequency increased (ca. $40 \mathrm{~Hz}$, corresponding to QCM mass loss, Table S1) and the dissipation reduced rapidly $\left(\sim 4 \times 10^{-6}\right)$ (Fig. 3a). The results can be rationalized by the loss of associated water and its displacement with the less dense ethanol. Furthermore, as ethanol swells cellulose less effectively than water, the model film may have undergonen a reduction in thickness and associated solvent. With time, the decline in dissipation is caused by a more "rigid" TOCNF film. These observations indicate that TOCNF became "solidified" in ethanol, which can be translated, in the context of wet spinning, to the formation of a semi-solid thread/filament. In fact, after ethanol immersion, TOCNF model films absorbed more water than before (Fig. 3a). At this stage, the mass of the film increased (Table S1) compared to that at the beginning of the experiment. This result suggests that during the first immersion in water, in the beginning of the experiment, the film did not become fully swollen. Upon subsequent exposure to water, after ethanol immersion, the film absorbed more water. This effect is less relevant or absent in the case of the ethanol-coagulated filaments.

Similar effects as those discussed before took place when exposing the TOCNF film to $\mathrm{HCl}$ solution (Fig. 3b), though the frequency increase was limited to $\sim 10 \mathrm{~Hz}$ (indicating a mass loss, Table S1). This can be interpreted as the result of the protonation of the carboxylate groups upon exposure to the acidic environment, promoting the release of water from the TOCNF film, which became more gel-like, due to lower surface charge. Furthermore, the heavier sodium ions bound to the carboxylate groups were replaced by lighter protons, which further decreases the film weight. As the film was rinsed with MilliQ water, this trend continued, in contrast to the opposite trend observed when rinsing after ethanol immersion (Fig. 3a). This implies that the gel-strengthening effect of the acid was irreversible in neutral $\mathrm{pH}$, whereas the coagulation induced by ethanol was temporal. The trends observed in the QCM-D experiments agree with the re-dispersability in water and the DVS results, discussed in other sections. Surprisingly, though, the TOCNF film underwent mass reduction (Table S1), even upon rinsing after $\mathrm{HCl}$ immersion (Fig. 3b). This may result from the presence of chlorine ions and associated water in the film during $\mathrm{HCl}$ flow.

The $\mathrm{CaCl}_{2}$ solution produced an effect on the TOCNF film that was in evident contrast with that observed for ethanol or $\mathrm{HCl}_{(\mathrm{aq})}$ : introduction of $\mathrm{CaCl}_{2(\mathrm{aq})}$ produced a reduction of frequency, by almost $100 \mathrm{~Hz}$ (mass increase, Table S1). This was accompanied by an increased dissipation (by $\sim 20 \times 10^{-6}$, Fig. 3c). Thus, it is likely that $\mathrm{Ca}^{2+}$ cations diffused into the film, carrying a large number of hydration water, resulting in a net mass increase (reduced resonance frequency). The high dissipation suggests that the calcium-containing film was rather soft and hydrated (viscous). Upon rinsing with MilliQ water, the effect of $\mathrm{CaCl}_{2}$ was largely (but not completely) reversed (Fig. 3c), as the excess calcium ions were removed.

Impact of coagulants on filament morphology and fibril orientation. SEM images in Fig. 4 (top and middle row) show that all filaments displayed a similar surface morphology as well as cross-section. However, a discrepancy was observed in the cross-section of the filaments coagulated in the organic solvents (Fig. S3). Most 


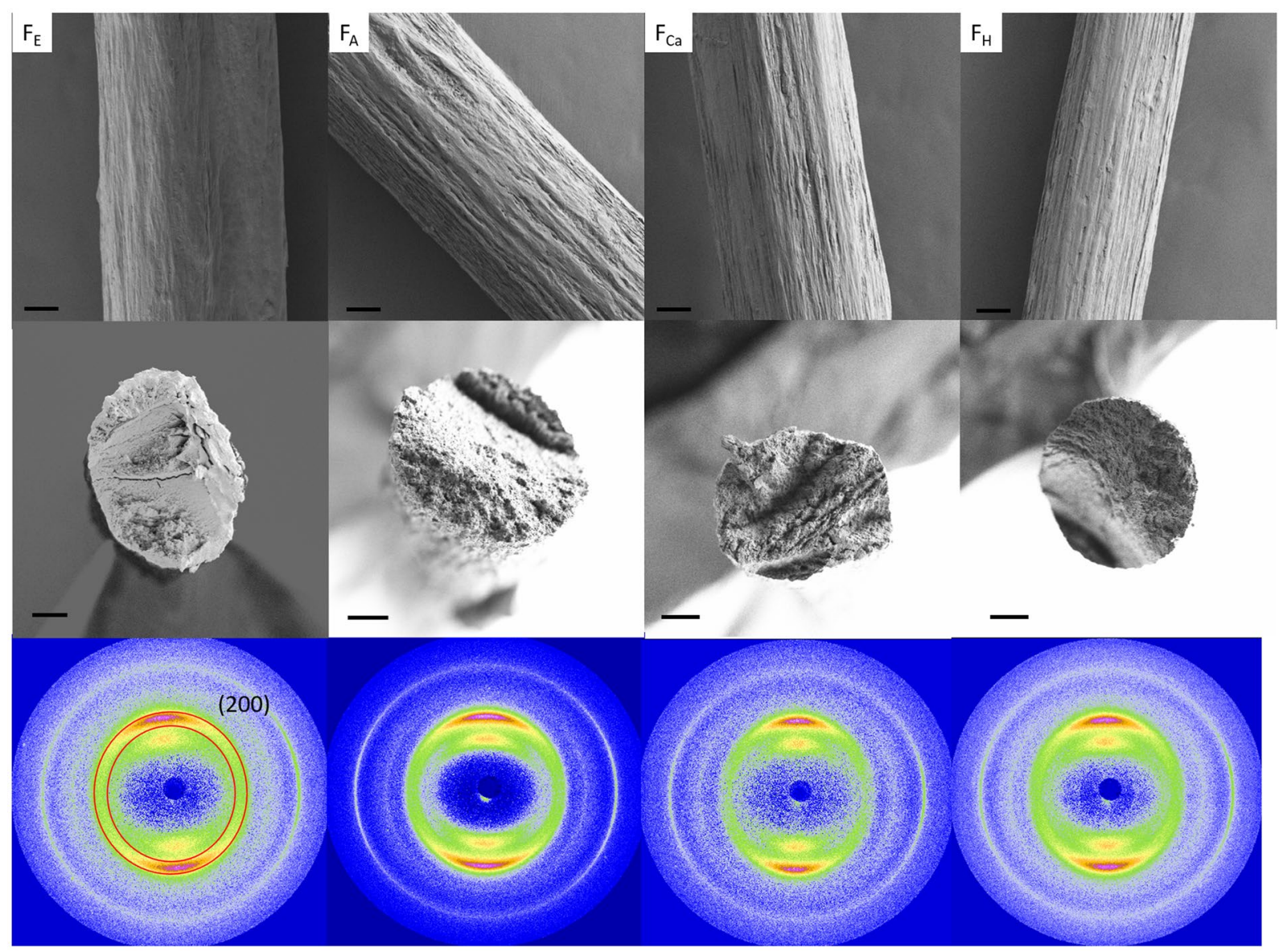

Figure 4. SEM images of the surface (top row, $20 \mu \mathrm{m}$ scale bar) and cross-section at break (middle row, $20 \mu \mathrm{m}$ scale bar) of filaments from different coagulants: ethanol $\left(\mathrm{F}_{\mathrm{Et}}\right)$, acetone $\left(\mathrm{F}_{\mathrm{Ac}}\right), \mathrm{HCl}\left(\mathrm{F}_{\mathrm{HCl}}\right)$ and $\mathrm{CaCl}_{2}\left(\mathrm{~F}_{\mathrm{Ca}}\right)$, as indicated. The bottom row includes the respective WAXS diffractograms.

$\mathrm{F}_{\mathrm{Et}}$ and few $\mathrm{F}_{\mathrm{Ac}}$ filaments displayed irregular cross-sections. In contrast, $\mathrm{F}_{\mathrm{Ca}}$ and $\mathrm{F}_{\mathrm{HCl}}$ filaments were more circular. Liu et al. and Ziabicki et al. have reported that the cross-section of regenerated cellulose fibers depends almost entirely on the coagulant employed in the system ${ }^{22,42}$. During coagulation, a moving shell associated with the coagulant and TOCNF is formed and moves toward the center of the forming filament ${ }^{15,22}$. The deformation of this thin layer at the beginning of coagulation, along with the difference of mass transfer rate (water and coagulants), determine the cross-sectional shape of the resulting filament. When the mass transfer rate of water is lower than that of the coagulant ( $\mathrm{HCl}$ and $\mathrm{CaCl}_{2}$ solutions), the filament swells and a circular cross section is favored. If the mass transfer rate of water is higher than that of the non-solvents (ethanol and acetone), a rigid surface layer is formed on the filament, which translates in a collapse of the cross section (filaments become thinner in the bath); hence, $\mathrm{F}_{\mathrm{Et}}$ and $\mathrm{F}_{\mathrm{Ac}}$ became densified and settled in the coagulation bath. The cross section of $\mathrm{F}_{\mathrm{Et}}$ and $\mathrm{F}_{\mathrm{Ac}}$ mainly depends on the filament deformability, before settling. In this case, $\mathrm{F}_{\mathrm{Et}}$ is less dense than $\mathrm{F}_{\mathrm{Ac}}$, before settling, making $\mathrm{F}_{\mathrm{Et}}$ to easily deform after settling at the bottom of the bath. Thus, $\mathrm{F}_{\mathrm{Et}}$ presented more irregular shapes, whereas $\mathrm{F}_{\mathrm{Ac}}$ was more circular in cross section (Fig. 4). Gel-like filaments coagulated from $\mathrm{CaCl}_{2}$ and $\mathrm{HCl}\left(\mathrm{F}_{\mathrm{Ca}}\right.$ and $\left.\mathrm{F}_{\mathrm{HCl}}\right)$, which were displaced to the surface of the bath and kept a more circular cross section.

The shear forces introduced during extrusion as well as the strain applied during restraint drying favor fibril alignment ${ }^{22}$. Such fibril orientation (orientation index and Herman's parameter) in the filaments was quantified by using WAXS (Table 2). The sharp arcs in the diffraction images confirm orientation along the filament axis direction (Fig. 4, bottom row). To determine the orientation of the (200) plane based on the diffractograms, the respective azimuthal profiles were plotted in Fig. S4. The peaks at 90 and 270 degrees provide further evidence that cellulose fibrils aligned along the filament axis. As shown in Fig. $5 \mathrm{a}$, all type of filaments were oriented to an approximately similar extent (orientation index between 0.7-0.75 and Herman's parameter between 0.5-0.57), which is explained by the similar shear conditions introduced during extrusion. However, some general observations seem to hold: $\mathrm{F}_{\mathrm{Ac}}$ had an orientation index close to that of $\mathrm{F}_{\mathrm{Et}}(0.7)$, but a slightly higher Herman's parameter ( 0.53 compared 0.5$)$. This is likely related to the faster coagulation rate, given that a shorter coagulation time allows less time for fibril relaxation in the coagulation bath ${ }^{17,22}$. Accordingly, $\mathrm{F}_{\mathrm{Ca}}$ and $\mathrm{F}_{\mathrm{HCl}}$ displayed better fibril orientation than $\mathrm{F}_{\mathrm{Ac}}$ and $\mathrm{F}_{\mathrm{Et}}$ (orientation indices of 0.72 and 0.75 and Herman's parameter of 0.54 to 0.57 , respectively). The results may be explained by the longer drying time and better fibril mobility during drying. Restrained drying imposes an extensional strain on the filament, as water evaporates but the filament is not allowed to shrink 


\begin{tabular}{|l|l|l|l|l|}
\hline Filaments & $\mathbf{F}_{\mathrm{Et}}$ & $\mathbf{F}_{\mathrm{Ac}}$ & $\mathbf{F}_{\mathrm{Ca}}$ & $\mathbf{F}_{\mathrm{HCl}}$ \\
\hline Coagulants & ethanol & acetone & $\mathrm{CaCl}_{2(\text { aq. })}$ & $\mathrm{HCl}_{(\mathrm{aq} .)}$ \\
\hline Young's modulus $(\mathrm{GPa})$ & $\begin{array}{l}12 \pm 1^{\mathrm{a}} \\
(15 \pm 1.4)^{\mathrm{b}}\end{array}$ & $\begin{array}{l}15 \pm 3^{\mathrm{a}} \\
(16.9 \pm 2.7)^{\mathrm{b}}\end{array}$ & $\begin{array}{l}17 \pm 3^{\mathrm{a}} \\
(18.6 \pm 3.7)^{\mathrm{b}}\end{array}$ & $\begin{array}{l}18 \pm 3.5^{\mathrm{a}} \\
(17 \pm 2.1)^{\mathrm{b}}\end{array}$ \\
\hline Tensile strength $(\mathrm{MPa})$ & $\begin{array}{l}207 \pm 10^{\mathrm{a}} \\
(232 \pm 13)^{\mathrm{b}}\end{array}$ & $\begin{array}{l}236 \pm 24^{\mathrm{a}} \\
(198 \pm 13.8)^{\mathrm{b}}\end{array}$ & $\begin{array}{l}344 \pm 32^{\mathrm{a}} \\
(315 \pm 31.7)^{\mathrm{b}}\end{array}$ & $\begin{array}{l}329 \pm 18^{\mathrm{a}} \\
(319 \pm 15.2)^{\mathrm{b}}\end{array}$ \\
\hline Strain $(\%)$ & $3.6 \pm 0.5$ & $4.6 \pm 1.0$ & $4.5 \pm 0.7$ & $2.7 \pm 0.6$ \\
\hline Tenacity $(\mathrm{cN} /$ tex $)$ & $12.6 \pm 1.9$ & $9.4 \pm 0.4$ & $16.4 \pm 3.2$ & $16.1 \pm 1.2$ \\
\hline $\mathrm{T}_{\text {onset }}\left({ }^{\circ} \mathrm{C}\right)$ & 226 & 229 & 243 & 248 \\
\hline Orientation index ${ }^{\mathrm{c}}$ & 0.7 & 0.68 & 0.72 & 0.75 \\
\hline Herman's parameter & 0.5 & 0.53 & 0.54 & 0.57 \\
\hline Limiting hornification $(\%)$ & 5.5 & 6.0 & 10.8 & 9.2 \\
\hline
\end{tabular}

Table 2. Properties of TOCNF filaments wet spun using different coagulants. ${ }^{\text {aN }}$ Normalized against crosssectional area obtained from micrometer, assuming a circular cross-section; ${ }^{b}$ Normalized against crosssectional area obtained via SEM images; ' Standard deviation $<10 \%$.

(a)

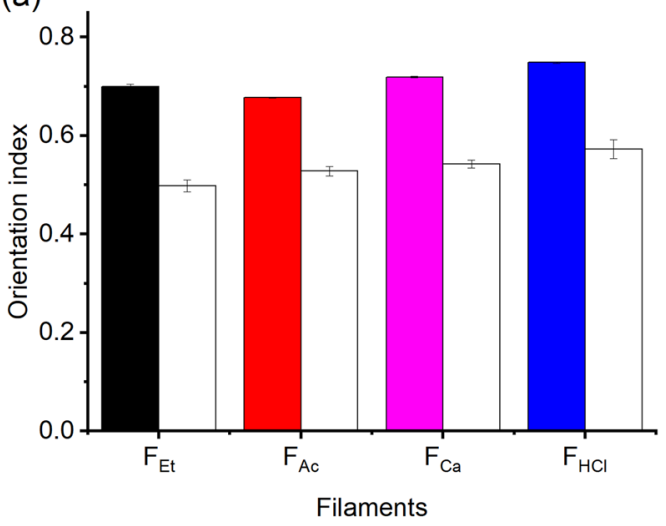

(b)

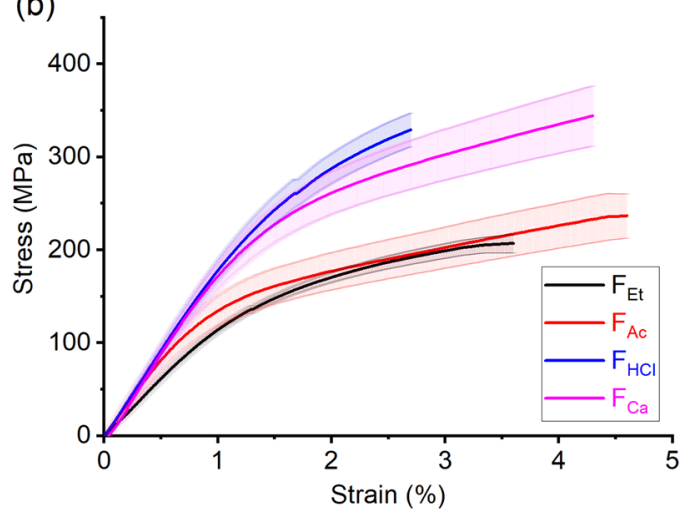

Figure 5. (a) Orientation index (filled bar) and Herman's parameter (open bar) calculated from azimuthal data. (b) Tensile stress profiles for TOCNF filaments obtained by using the different coagulants. (Note: The highlighted area indicated the actual error bar in stress).

in the axial direction. Such extensional strain tends to orient fibrils along the filament axis. Although $\mathrm{F}_{\mathrm{Ca}}$ was dried in the same way, the drying speed was much faster than that of $\mathrm{F}_{\mathrm{HCl}}$ and the fibrils were already largely locked by $\mathrm{Ca}$ ions, which prevented the interfibrillar sliding during drying (Fig. 1).

Effect of coagulant on the mechanical strength of the filaments. Obviously, the value of the cross-sectional area, determines the calculated values of tensile strength and Young's modulus ${ }^{19}$. Thus, such parameter was measured using both micrometer (assuming a circular cross-section) and SEM imaging (considering the actual perimeter after image processing). Figure $5 \mathrm{~b}$ presents the stress-strain curves normalized against the cross-sectional area obtained by a micrometer. For comparison, Fig. S5 shows the stress-strain curves normalized against the cross-sectional area from the SEM imaging. A difference can be seen in these data, as a result of the variations in cross sections, most evident in the case of $\mathrm{F}_{\mathrm{Et}}$ filaments. In order to remove any influence of the determined cross-sectional area, the filament tenacity, that does not depend on the cross section, was calculated and listed in Table 2.

Regardless of the method to measure the cross-sectional area, all the data in Figs 5b, S5 and Table 2 clearly indicate that the filaments coagulated in aqueous electrolyte solutions possessed higher tensile strength and tenacity (315-344 MPa and $16.4 \mathrm{cN} /$ tex for $\mathrm{F}_{\mathrm{Ca}}$, and 319-329 MPa and $16.1 \mathrm{cN} /$ tex for $\mathrm{F}_{\mathrm{HCl}}$, respectively) than the ones coagulated with the organic solvents $\left(207-232 \mathrm{MPa}\right.$ and $12.6 \mathrm{cN} /$ tex for $\mathrm{F}_{\mathrm{E}}$, and $198-236 \mathrm{MPa}$ and $9.4 \mathrm{cN} /$ tex for $\mathrm{F}_{\mathrm{Ac}}$ respectively). This can be explained by the fact that $\mathrm{F}_{\mathrm{Et}}$ and $\mathrm{F}_{\mathrm{HAc}}$, having sodium counterions, underwent reduced fibrillar bond strength and were less capable for interfibrillar hydrogen boning, thus limiting the mechanical strength ${ }^{33,43}$. In contrast, the carboxylate groups in $\mathrm{F}_{\mathrm{HCl}}$ fibrils, which are protonated in hydrochloric acid, facilitate the hydrogen bond formation. In associated work, Benitez et al. showed that TOCNF films with $\mathrm{Na}$ as counterion had a much better modulus than those that were protonated. This is because the $\mathrm{H}^{+}$introduced in the bulk dispersion results in fibril flocculation, before film formation ${ }^{43}$. On the other hand, the higher tensile strength of $\mathrm{F}_{\mathrm{Ca}}$ can be attributed to the interfibrillar interactions caused by calcium cations, as discussed in the section 'Impact of coagulant on wet spinning of TOCNF'. Finally, only small differences were noticed in strain at break and Young's modulus for the different filaments, obtained either with the organic or aqueous coagulants. This can be attributed to the similar fibril orientations (Fig. 5a). 

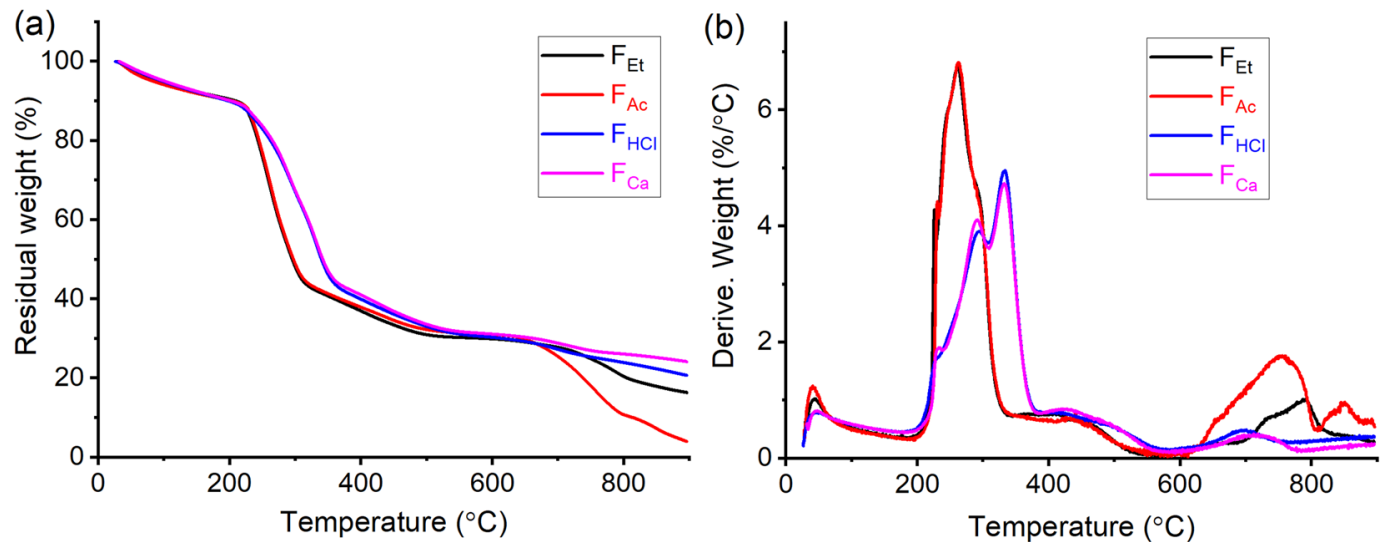

Figure 6. The thermal degradation curve from room temperature to $900{ }^{\circ} \mathrm{C}(\mathbf{a})$; The DTG curve of filaments from room temperature to $900^{\circ} \mathrm{C}(\mathbf{b})$, for filaments obtained using different coagulants.

Counterion effect on filament thermal stability. A similar thermo-gravimetric behavior was observed for all the filaments, within $20-900^{\circ} \mathrm{C}$ (Fig. 6 a). Water evaporated from the filaments at $\leq 100^{\circ} \mathrm{C}$, followed by cellulose chain session at $200-400{ }^{\circ} \mathrm{C}$. Finally, the filaments were carbonized at temperatures up to $900^{\circ} \mathrm{C}$. $\mathrm{F}_{\mathrm{Et}}$ and $\mathrm{F}_{\mathrm{Ac}}$ (from organic coagulants) started to degrade at similar temperatures $\left(\mathrm{T}_{\text {onset }}\right.$ of 226 and $229^{\circ} \mathrm{C}$, respectively), whereas the $\mathrm{T}_{\text {onset }}$ shifted to higher temperatures $\left(248\right.$ and $243^{\circ} \mathrm{C}$ ) for $\mathrm{F}_{\mathrm{Ca}}$ and $\mathrm{F}_{\mathrm{HCl}}$, respectively (Table 2). From the derivative thermogravimetry (DTG, Fig. 6b), it can be observed that the peak corresponding to maximum degradation rate, between $200-400^{\circ} \mathrm{C}$, shifted to higher temperatures from $\mathrm{F}_{\mathrm{E}}, \mathrm{F}_{\mathrm{Ac}}$ to $\mathrm{F}_{\mathrm{Ca}}, \mathrm{F}_{\mathrm{HCl}}$. This is because filaments obtained by coagulation from organic solvents contained a large number of sodium ions (Fig. 2a,b), which have been shown to catalyze cellulose degradation at low temperatures ${ }^{44,45}$. In addition, a higher residual weight was noticed for $\mathrm{F}_{\mathrm{Ca}}$ and $\mathrm{F}_{\mathrm{HCl}}$ compared to $\mathrm{F}_{\mathrm{Ac}}$ and $\mathrm{F}_{\mathrm{Et}}$. These results are consistent with Kleen's observation that cellulose in hydrogen or calcium forms can increase the pyrolytic yield of anhydro-sugars whereas cellulose with sodium counterions would present a lower yield ${ }^{46}$. As such, $\mathrm{F}_{\mathrm{Ca}}$ and $\mathrm{F}_{\mathrm{HCl}}$ were more thermally stable than $\mathrm{F}_{\mathrm{Et}}$ and $\mathrm{F}_{\mathrm{Ac}}$.

Coagulant effect on filament's water stability/re-dispersability and moisture sorption. Different interactions with liquid were observed after soaking the filaments in water (Fig. S6). $\mathrm{F}_{\mathrm{Et}}$ and $\mathrm{F}_{\mathrm{Ac}}$, with $\mathrm{Na}^{+}$as counter ions, swelled and turned into transparent gels immediately after immersion in water. However, no noticeable swelling was observed for $\mathrm{F}_{\mathrm{HCl}}$, given that fibrils with low surface charges have limited affinity to water ${ }^{18}$. Similar phenomenon took place for $\mathrm{F}_{\mathrm{C}}$, which barely swelled owing to the ionic interactions that prevented water from penetrating the interfibrillar spaces. Similar trend has been shown for TOCNF films: less water was absorbed in the presence of $\mathrm{Ca}^{2+}$ counterions (while intermediate and higher degrees of water swelling were recorded in systems with $\mathrm{H}^{+}$and $\mathrm{Na}^{+}$counterions $)^{31}$. Dong et al. have reported that TOCNF films bearing $\mathrm{Na}^{+}$counterions can be easily re-dispersed in water, with the help of ultrasound ${ }^{36}$. The re-dispersability of wet spun filaments was tested by immersion and sonication in water for 1 hour. The filaments formed with no counterion exchange $\left(\mathrm{F}_{\mathrm{Et}}\right.$ and $\mathrm{F}_{\mathrm{Ac}}$ ) swelled significantly and turned into transparent gels; however, they remained cohesive and were not re-dispersed in water. In contrast, the $\mathrm{F}_{\mathrm{HCl}}$ and $\mathrm{F}_{\mathrm{Ca}}$ retained the filament shape, without noticeable changes after sonication.

The moisture sorption capacity of the filaments was followed by dynamic vapor sorption (DVS), cycling relative humidity (RH) between 0 to $95 \%$ for seven times (Fig. 7a). Clearly, in every cycle $\mathrm{F}_{\mathrm{Ac}}$ and $\mathrm{F}_{\mathrm{Et}}$ sorbed more moisture than $\mathrm{F}_{\mathrm{HCl}}$ and $\mathrm{F}_{\mathrm{Ca}}$. This finding agrees with the observation that $\mathrm{F}_{\mathrm{H}}$ and $\mathrm{F}_{\mathrm{Ca}}$ are more resistant to water, as discussed above. Furthermore, compared to the effect of ethanol, the results are supported by the decreased reversibility of the coagulation effect promoted by $\mathrm{HCl}$ and $\mathrm{CaCl}_{2}$, as observed in QCM experiments. As such, it can be concluded that $\mathrm{F}_{\mathrm{H}}$ and $\mathrm{F}_{\mathrm{Ca}}$ are the filaments that are most resistant to water, in both liquid and vapor forms, owing to reduced surface charge $\left(\mathrm{F}_{\mathrm{HCl}}\right)$ or electrostatic interactions $\left(\mathrm{F}_{\mathrm{Ca}}\right)$.

A progressive decline in the equilibrium moisture content (EMC) at 95\% RH was observed after each DVS cycle. This occurs most likely due to irreversible changes occurring in the filament, e.g., "hornification"47-49. By fitting the EMC with an exponential function, the limiting hornification (LH) was obtained to determine the relative decrease in EMC at infinite number of cycles and compared to the first cycle (Eq. 4). The LH for each sample is presented in Fig. $7 \mathrm{~b}$ and Table 2. Filaments coagulated in organic coagulants $\left(\mathrm{F}_{\mathrm{Et}}, \mathrm{F}_{\mathrm{Ac}}\right)$ were the least hornified (LH 5-6\%), most probably because of their high surface charge that inhibits the effects associated with hornification, such as irreversible hydrogen bond formation, pore closure and fibril aggregation ${ }^{47}$. For the other filaments $\left(\mathrm{F}_{\mathrm{Ca}}\right.$ and $\left.\mathrm{F}_{\mathrm{HCl}}\right)$, the TOCNF surface charge is reduced due to electrostatic screening $\left(\mathrm{CaCl}_{2}\right)$ or protonation $(\mathrm{HCl})$, which makes these filaments more susceptible to hornification. Similar observations have been reported for the hornification of filaments wet-spun from CNF bearing different surface charge density ${ }^{19}$. The moisture sorption phenomenon was further characterized using the parallel exponential kinetics model (see supporting information, Fig. S7). 
(a)

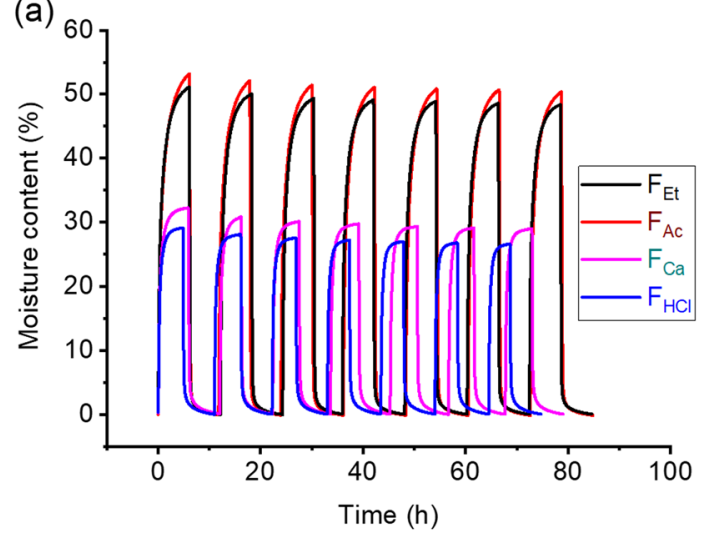

(b)

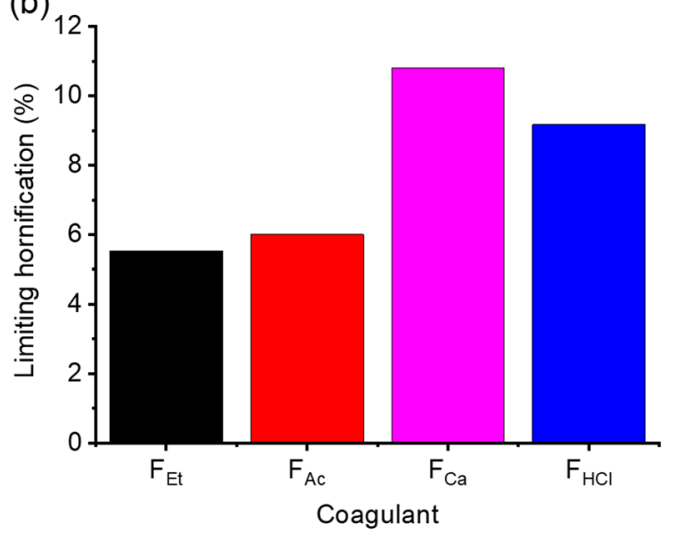

Figure 7. (a) Full moisture DVS sorption isotherms of wet-spun filaments at RH cycles between $0 \%$ to $95 \%$. (b) Limiting hornification (LH) value calculated for the filaments.

\section{Conclusions}

Wet spinning of TOCNF was carried out using spinning baths comprising either organic nonsolvents (ethanol or acetone) or electrolyte solutions $\left(\mathrm{NaCl}_{\mathrm{aq}}, \mathrm{CaCl}_{2 \mathrm{aq}}\right.$ or $\left.\mathrm{HCl}_{\mathrm{aq}}\right)$. Enhanced interfibrillar interactions were observed after solvent exchange (ethanol and acetone anti-solvents) or via electrostatic screening and complexation (aqueous electrolytes). A correlation between the coagulant type, filament morphology, as well as fibril orientation and the corresponding physical properties is found. The counterions of carboxylate groups present in TOCNF played a critical role in the resultant properties of the filament. The physical aggregation that occurred in the organic solvent retained fibrils in the sodium form $(\mathrm{CNF}-\mathrm{COONa})$. This yielded filaments $\left(\mathrm{F}_{\mathrm{Et}}\right.$ and $\left.\mathrm{F}_{\mathrm{Ac}}\right)$ with relatively weaker mechanical strength, lower thermal and water stability, and higher moisture sorption capacity. Those formed via hydrogen bonding or chemical complexation $\left(\mathrm{F}_{\mathrm{HCl}}\right.$ and $\mathrm{F}_{\mathrm{Ca}}$ respectively) presented the opposite characteristics. A more circular cross-section was observed for such filaments.

\section{Materials and Methods}

TEMPO oxidized cellulose nanofibrils (TOCNF). Never dried bleached birch fibrils (UPM, Pietarsaari Mill) were oxidized by 2,2,6,6-tetramethylpiperidine-1-oxyl (TEMPO, Sigma-Aldrich) at $\mathrm{pH} 10$. After washing with deionized water, the oxidized fibrils were passed through high-pressure microfluidization (Microfluidics Corp., USA), yielding TEMPO oxidized cellulose nanofibrils (TOCNF) of $1.6 \mathrm{wt} \%$ solids content and $0.6 \mathrm{mmol} \mathrm{g}^{-1}$ carboxylic groups. The TOCNF used in this work was in the sodium form.

Wet spinning of TOCNF. Four different coagulants (ethanol, acetone, and aqueous electrolytes, $\mathrm{HCl}$ and $\mathrm{CaCl}_{2}$ ) were used to investigate their influence on wet spinning. TOCNF was loaded into a $50 \mathrm{ml}$ syringe and extruded $(10 \mathrm{ml} / \mathrm{min})$ through a tube $(44.5 \mathrm{~cm}$ length, $6 \mathrm{~mm}$ inner diameter), followed by a needle $(3.7 \mathrm{~cm}$ length and $1.2 \mathrm{~mm}$ inner diameter) and finally into a the spinning bath that contained either ethanol or acetone as non-solvent or aqueous solutions containing $\mathrm{CaCl}_{2}(10 \mathrm{wt} \%)$ or $\mathrm{HCl}(\mathrm{pH} 2)$. The drying rate was estimated qualitatively as the time lapsed soon after picking the filament from the bath until it remained straight when suspended in air and with no observable shrinkage upon removal from the holder. At least ten specimen were considered. Here, the term coagulation is used loosely since the involved phenomena can be quite complex and different than the typical solvent exchange. The collected filaments were dried in ambient conditions under restrained drying (by fixing both ends of the filaments). The drying time was recorded from the time the given filament was withdrawn from the spinning bath until it became dried, forming straight filament. The filaments collected from $\mathrm{CaCl}_{2}$ and $\mathrm{HCl}$ solutions required an extra washing steps, which were carried out by dipping the filaments in fresh water (4 times), followed by immersion in water for $10 \mathrm{~min}$ and $2 \mathrm{~h}$, respectively. After each washing step, the filaments were dried in air, also under restricted shrinkage. The drying time was recorded from the time the filament was picked up from the bath, until the filament stayed straight in the air, without shrinking after removal of one of the two holding ends. The dry filaments obtained from coagulation in ethanol, acetone, $\mathrm{CaCl}_{2}$ and $\mathrm{HCl}$ are thereafter referred to as $\mathrm{F}_{\mathrm{Et}}, \mathrm{F}_{\mathrm{Ac}}, \mathrm{F}_{\mathrm{Ca}}$ and $\mathrm{F}_{\mathrm{HCl}}$, respectively.

Continuous spinning. A continuous spinning test was conducted using the same setup as above with an addition of a winder (diameter of $22 \mathrm{~cm}$ ) for filament collection. TOCNF was extruded at $0.64 \mathrm{~m} \mathrm{~min}^{-1}$ and the winding speed was controlled at $3.6 \mathrm{~m} \mathrm{~min}^{-1}$.

Tensile strength. The effect of coagulant on the mechanical strength of the filament was determined with an Instron 5944 Single Column, Tabletop Universal Testing System, operated in tensile mode with a load cell of $5 \mathrm{~N}$. At least seven specimens per sample were measured with gauge length of $2 \mathrm{~cm}$ and stretching rate of $2 \mathrm{~mm} \mathrm{~min}^{-1}$. Prior to testing, filaments were conditioned overnight at $50 \%$ humidity and $23^{\circ} \mathrm{C}$. The filament cross-sectional areas were obtained by using a micrometer, and also from imaging with a scanning electron microscope (using image-processing software ImageJ to determine the perimeter and the actual cross-sectional area). Ten specimen were measured for each type of filaments. Note: for the cross-section area obtained from SEM, an average value was obtained from at least eight specimens tested for each sample. 
Thermogravimetric analysis (TGA). The filament thermal stability was determined under $\mathrm{N}_{2}$ flow using TA Instrument (Thermo Gravimetric Analyzer Q500). Filaments were cut into $\sim 2 \mathrm{~mm}$ length and heated up to $900^{\circ} \mathrm{C}$ from room temperature with a heating rate of $10^{\circ} \mathrm{C} \mathrm{min}^{-1}$.

Scanning electron microscopy (SEM) and energy dispersive X-ray spectroscopy (EDX). Filament morphology and cross sections at break were observed using Zeiss SIGMA VP (Carl Zeiss Microscopy Ltd, Cambridge, UK) at $1.6 \mathrm{kV}$ with a working distance of $1 \mathrm{~cm}$. Before imaging, the filaments were deposited with 5 $\mathrm{nm}$-thick Pt/Pd coating. The fracture was made by bending the frozen filaments in liquid $\mathrm{N}_{2}$. For detection of elements (Na and $\mathrm{Ca}$ ), EDX spectra were recorded in a JEOL JSM-7500FA SEM (Japan) at 15kV acceleration voltage.

Wide angle X-ray scattering (WAXS). The fibril orientation of the filaments was determined with a MicroMax-007 X-ray generator (Rigaku, Japan). WAXS was performed in transmission mode with an X-ray wavelength of $1.54 \AA$, a beam size of $120 \mu \mathrm{m}$ and an exposure time of 10 minutes. A Mar345 plate detector was employed to collect sample diffraction patterns with $200 \mathrm{~mm}$ distance of sample-to-detector. The filaments were aligned horizontally and placed perpendicular to the beam. Before evaluation, the background was subtracted from the diffraction patterns. Based on azimuthal intensity distribution profiles, orientation index $(\pi)$ and Herman's orientation parameter (S) were calculated according to Eqs (1) and (2):

$$
\pi=\frac{180^{\circ}-F W H M}{180^{\circ}}
$$

where FWHM is the full width at the half maximum (in degrees) of one of the two peaks in the azimuthal intensity distribution profile. $\pi$ was calculated for both peaks and their average reported.

$$
S=\frac{3}{2}\left\langle\cos ^{2} \gamma\right\rangle-\frac{1}{2}
$$

Assuming cylindrical symmetry in the filament, the average cosine $\left\langle\cos ^{2} \gamma\right\rangle$ was obtained from the azimuthal angle $\varphi$ according to Eq. $(3)^{50}$.

$$
\left\langle\cos ^{2} \gamma=1-2 \cos ^{2} \varphi\right\rangle
$$

where

$$
\left\langle\cos ^{2} \varphi\right\rangle=\frac{\sum_{\varphi_{0}}^{\varphi_{0}+\pi / 2} I(\varphi) \sin \varphi \cos ^{2} \varphi}{\sum_{\varphi_{0}}^{\varphi_{0}+\pi / 2} I(\varphi) \sin \varphi}
$$

here, $I(\varphi)$ is the intensity detected at azimuthal angle $\varphi$, and $\varphi_{0}$ is the azimuthal angle in the beginning of the range used for the calculation of the average $\operatorname{cosine}\left\langle\cos ^{2} \varphi\right\rangle$. $S$ was calculated at $\varphi_{0}$ of $0, \pi / 2, \pi$ and $3 \pi / 2$ and the average of these values is reported. A value of 1 for the orientation parameter indicates a fully oriented structure while 0 means a disordered structure.

Quartz crystal microbalance with dissipation (QCM-D). The effect of different coagulants on TOCNF was studied with the QCM-D technique using a Q-Sense E4 apparatus (Q-Sense, Sweden). Firstly, UV/ozonized QCM-D gold crystals were coated with an anchor layer of polyethylenimine (PEI) by immersing them in $0.1 \mathrm{~g} / \mathrm{L}$ aqueous PEI solution for $15 \mathrm{~min}$. After rinsing with MilliQ water and drying with $\mathrm{N}_{2}$ gas, the PEI-covered crystals were first spin-coated with MilliQ water to wet the surface $(3000 \mathrm{rpm}, 30 \mathrm{~s})$ and then with a $1 \mathrm{~g} / \mathrm{L} \mathrm{TOCNF}$ dispersion in MilliQ water $(3000 \mathrm{rpm}, 60 \mathrm{~s})$. Finally, the obtained TOCNF films were dried with $\mathrm{N}_{2}$ flow and heat-treated at $80^{\circ} \mathrm{C}$ for $10 \mathrm{~min}$.

After placing the TOCNF-covered crystals in the QCM-D chambers, they were rinsed with degassed MilliQ water until the frequency and dissipation signals stabilized. After $\sim 5 \mathrm{~min}$, degassed ethanol or aqueous solutions $\left(1 \mathrm{M} \mathrm{CaCl}_{2}\right.$ or $\mathrm{HCl}$ at $\left.\mathrm{pH} 2\right)$ was introduced for $\sim 30 \mathrm{~min}$. Subsequently, the films were rinsed with degassed MilliQ water. All QCM-D experiments were conducted at least twice at $23^{\circ} \mathrm{C}$ and under a constant flow of $100 \mu \mathrm{L} / \mathrm{min}$.

Dynamic vapor sorption (DVS). Dynamic vapor sorption (DVS, Surface Measurement Systems, UK) was used to determine the water vapor sorption isotherms of the filaments. Filaments ( $\sim 10 \mathrm{mg}, \sim 5 \mathrm{~mm}$ in length) were loaded into the sample pan hanging from a microbalance in a climate-controlled chamber. Firstly, the sample was allowed to stabilize (change in mass below $0.002 \% / \mathrm{min}$ over a period of 10 minutes) at a relative humidity (RH) of $0 \%$. Secondly, the RH was increased to $95 \%$ and maintained steady until the sample mass stabilized, followed by decreasing the $\mathrm{RH}$ back to $0 \%$. In this way, $\mathrm{RH}$ was cycled between $0 \%$ (moisture desorption) and $95 \%$ (moisture sorption) for seven times in total. The relative increase in sample mass compared to the mass after the first drying at $0 \% \mathrm{RH}$ corresponds to the moisture content of the sample at $95 \% \mathrm{RH}$.

The changes in the equilibrium moisture content (EMC) obtained at the end of each cycle at $95 \% \mathrm{RH}$, reflect the effect of the so-called "hornification" on the sorption capacity of the sample ${ }^{48}$. The EMC as a function of the humidity cycle was fitted to an exponential function. Using this fitting, the limiting hornification (LH) was estimated according to

$$
L H=\frac{E M C_{1}-E M C_{n}}{E M C_{1}} \times 100 \%,
$$


where $E M C_{1}$ is the EMC at the end of the first cycle at $\mathrm{RH} 95 \%$ and $E M C_{n}$ at the end of the ${ }^{\text {th }}$ cycle when $n$ approaches infinity. $E M C_{n}$ was estimated according to the exponential fit of the EMC measured at the end of each of the seven cycles. Notably, the EMC values obtained by DVS contain the contribution of external surfaces, which are not susceptible to hornification. As such, Eq. (4) yields the limiting hornification as a percentage of total initial sorption capacity.

Received: 5 June 2019; Accepted: 14 October 2019;

Published online: 13 November 2019

\section{References}

1. Lundahl, M. J., Klar, V., Wang, L., Ago, M. \& Rojas, O. J. Spinning of cellulose nanofibrils into filaments: A review. Industrial and Engineering Chemistry Research 56, 8-19 (2017).

2. Kontturi, E. et al. Advanced Materials through Assembly of Nanocelluloses. Advanced Materials 30, 1703779 (2018).

3. Mittal, N. et al. Multiscale Control of Nanocellulose Assembly: Transferring Remarkable Nanoscale Fibril Mechanics to Macroscale Fibers. ACS Nano 12, 6378-6388 (2018).

4. Clemons, C. Nanocellulose in Spun Continuous Fibers: A Review and Future Outlook. Journal of Renewable Materials 4, 327-339 (2016).

5. Mittal, N. et al. Ultrastrong and Bioactive Nanostructured Bio-Based Composites. ACS Nano 11, 5148-5159 (2017).

6. Toivonen, M. S. et al. Interfacial Polyelectrolyte Complex Spinning of Cellulose Nanofibrils for Advanced Bicomponent Fibers. Biomacromolecules 18, 1293-1301 (2017).

7. Yao, J. et al. Macrofibers with High Mechanical Performance Based on Aligned Bacterial Cellulose Nanofibers. ACS Applied Materials \& Interfaces 9, 20330-20339 (2017).

8. Shen, Y. et al. High velocity dry spinning of nanofibrillated cellulose (CNF) filaments on an adhesion controlled surface with low friction. Cellulose 23, 3393-3398 (2016).

9. Hagström, B. et al. Continuous Assembly of Cellulose Nanofibrils and Nanocrystals into Strong Macrofibers through Microfluidic Spinning. Advanced Materials Technologies 4, 1800557 (2018).

10. Ghasemi, S., Tajvidi, M., Gardner, D. J., Bousfield, D. W. \& Shaler, S. M. Effect of wettability and surface free energy of collection substrates on the structure and morphology of dry-spun cellulose nanofibril filaments. Cellulose 25, 6305-6317 (2018).

11. Zhang, K. \& Liimatainen, H. Hierarchical Assembly of Nanocellulose-Based Filaments by Interfacial Complexation. Small 14, 1801937 (2018).

12. Tripathi, A., Ago, M., Khan, S. A. \& Rojas, O. J. Heterogeneous Acetylation of Plant Fibers into Micro- and Nanocelluloses for the Synthesis of Highly Stretchable, Tough, and Water-Resistant Co-continuous Filaments via Wet-Spinning. ACS Applied Materials \& Interfaces 10, 44776-44786 (2018).

13. Torres-Rendon, J. G., Schacher, F. H., Ifuku, S. \& Walther, A. Mechanical performance of macrofibers of cellulose and chitin nanofibrils aligned by wet-stretching: A critical comparison. Biomacromolecules 15, 2709-2717 (2014).

14. Iwamoto, S., Isogai, A. \& Iwata, T. Structure and mechanical properties of wet-spun fibers made from natural cellulose nanofibers. Biomacromolecules 12, 831-836 (2011).

15. Walther, A., Timonen, J. V. I., Díez, I., Laukkanen, A. \& Ikkala, O. Multifunctional High-Performance Biofibers Based on WetExtrusion of Renewable Native Cellulose Nanofibrils. Advanced Materials 23, 2924-2928 (2011).

16. Mertaniemi, H. et al. Human stem cell decorated nanocellulose threads for biomedical applications. Biomaterials 82, 208-220 (2016).

17. Brouzet, C., Mittal, N., Lundell, F. \& Söderberg, L. D. Characterizing the Orientational and Network Dynamics of Polydisperse Nanofibers on the Nanoscale. Macromolecules 52, 2286-2295 (2019).

18. Mohammadi, P., Toivonen, M. S., Ikkala, O., Wagermaier, W. \& Linder, M. B. Aligning cellulose nanofibril dispersions for tougher fibers. Scientific Reports 7, 11860 (2017).

19. Lundahl, M. J. et al. Strength and Water Interactions of Cellulose I Filaments Wet-Spun from Cellulose Nanofibril Hydrogels. Scientific Reports 6, 30695 (2016).

20. Håkansson, K. M. O. et al. Hydrodynamic alignment and assembly of nanofibrils resulting in strong cellulose filaments. Nature Communications 5 (2014).

21. Kafy, A. et al. Cellulose long fibers fabricated from cellulose nanofibers and its strong and tough characteristics. Scientific Reports 7 (2017).

22. Liu, C.-K., Cuculo, J. A. \& Smith, B. Diffusion competition between solvent and nonsolvent during the coagulation process of cellulose/ammonia/ammonium thiocynate fiber spinning system. Journal of Polymer Science Part B: Polymer Physics 28, 449-465 (1990).

23. Ferguson, J. \& Ibrahim, K. The wet spinning of secondary cellulose acetate: Solution rheology and filament spinnability. Polymer 10, 135-145 (1969).

24. Mortimer, S. A. \& Péguy, A. A. The formation of structure in the spinning and coagulation of lyocell fibres. Cellulose Chemistry and Technology 30, 117-132 (1996).

25. Wang, L. et al. Conductive carbon microfibers derived from wet-spun lignin/nanocellulose hydrogels. ACS Sustainable Chemistry \& Engineering acssuschemeng.8b06081, https://doi.org/10.1021/acssuschemeng.8b06081 (2019).

26. Laity, P. R., Glover, P. M., Barry, A. \& Hay, J. N. Studies of non-solvent induced polymer coagulation by magnetic resonance imaging. Polymer 42, 7701-7710 (2001).

27. Van De Witte, P., Dijkstra, P. J., Van Den Berg, J. W. A. \& Feijen, J. Phase separation processes in polymer solutions in relation to membrane formation. Journal of Membrane Science 117, 1-31 (1996).

28. Mostafa Nowee, S., Abbas, A. \& Romagnoli, J. A. Antisolvent crystallization: Model identification, experimental validation and dynamic simulation. Chemical Engineering Science 63, 5457-5467 (2008).

29. Wågberg, L. et al. The build-up of polyelectrolyte multilayers of microfibrillated cellulose and cationic polyelectrolytes. Langmuir $\mathbf{2 4}$, 784-795 (2008)

30. Chau, M. et al. Ion-Mediated Gelation of Aqueous Suspensions of Cellulose Nanocrystals. Biomacromolecules 16, 2455-2462 (2015).

31. Shimizu, M., Saito, T. \& Isogai, A. Water-resistant and high oxygen-barrier nanocellulose films with interfibrillar cross-linkages formed through multivalent metal ions. Journal of Membrane Science 500, 1-7 (2016).

32. Fukuzumi, H., Tanaka, R., Saito, T. \& Isogai, A. Dispersion stability and aggregation behavior of TEMPO-oxidized cellulose nanofibrils in water as a function of salt addition. Cellulose 21, 1553-1559 (2014).

33. Fall, A. B., Lindström, S. B., Sundman, O., Ödberg, L. \& Wågberg, L. Colloidal Stability of Aqueous Nanofibrillated Cellulose Dispersions. Langmuir 27, 11332-11338 (2011).

34. Verwey, E. J. W. Theory of the Stability of Lyophobic Colloids. The. Journal of Physical and Colloid Chemistry 51, 631-636 (1947).

35. Derjaguin, B. \& Landau, L. Theory of the stability of strongly charged lyophobic sols and of the adhesion of strongly charged particles in solutions of electrolytes. Progress in Surface Science 43, 30-59 (2002). 
36. Dong, X. M. \& Gray, D. G. Effect of Counterions on Ordered Phase Formation in Suspensions of Charged Rodlike Cellulose Crystallites. Langmuir 13, 2404-2409 (1997).

37. Fukui, S., Ito, T., Saito, T., Noguchi, T. \& Isogai, A. Counterion design of TEMPO-nanocellulose used as filler to improve properties of hydrogenated acrylonitrile-butadiene matrix. Composites Science and Technology 167, 339-345 (2018).

38. Saito, T. \& Isogai, A. Ion-exchange behavior of carboxylate groups in fibrous cellulose oxidized by the TEMPO-mediated system. Carbohydrate Polymers 61, 183-190 (2005).

39. Shimizu, M., Saito, T. \& Isogai, A. Bulky quaternary alkylammonium counterions enhance the nanodispersibility of 2,2,6,6-tetramethylpiperidine-1-oxyl-oxidized cellulose in diverse solvents. Biomacromolecules 15, 1904-1909 (2014).

40. Tyn, M. Temperature and concentration dependence of mutual diffusion coefficients of some binary liquid systems. Journal of Chemical and Engineering 20, 310-316 (1975).

41. Schönherr, J. Calcium chloride penetrates plant cuticles via aqueous pores. Planta 212, 112-118 (2000).

42. Ziabicki, A. Fundamentals of Fibre Formation: The Science of Fiber Spinning and Drawing. in New York: Wiley 488 (Wiley, 1976), https://doi.org/10.1007/s00436-008-1235-6.

43. Benítez, A. J. \& Walther, A. Counterion Size and Nature Control Structural and Mechanical Response in Cellulose Nanofibril Nanopapers. Biomacromolecules 18, 1642-1653 (2017).

44. Shao, Y., Guizani, C., Grosseau, P., Chaussy, D. \& Beneventi, D. Thermal characterization and kinetic analysis of microfibrillated cellulose/lignosulfonate blends. Journal of Analytical and Applied Pyrolysis 124, 25-34 (2017).

45. Fukuzumi, H., Saito, T., Okita, Y. \& Isogai, A. Thermal stabilization of TEMPO-oxidized cellulose. Polymer Degradation and Stability 95, 1502-1508 (2010).

46. Gellerstedt, G. \& Kleen, M. Influence of inorganic species on the formation of polysaccharide and lignin degradation products in the analytical pyrolysis of pulps. Journal of Analytical and Applied Pyrolysis 35, 15-41 (1995).

47. Suchy, M., Kontturi, E. \& Vuorinen, T. Impact of Drying on Wood Ultrastructure: Similarities in Cell Wall Alteration between Native Wood and Isolated Wood-Based Fibers. Biomacromolecules 11, 2161-2168 (2010).

48. Pönni, R., Rautkari, L., Hill, C. A. S. \& Vuorinen, T. Accessibility of hydroxyl groups in birch kraft pulps quantified by deuterium exchange in D2O vapor. Cellulose 21, 1217-1226 (2014).

49. Jayme, G. Micromeasurements of the swelling of pulps. Papierfabr - Wochenbl Papierfabr 6, 187-194 (1944).

50. Nishiyama, Y., Kuga, S., Wada, M. \& Okano, T. Cellulose microcrystal film of high uniaxial orientation. Macromolecules 30, 6395-6397 (1997).

\section{Acknowledgements}

We acknowledge funding support from the European Research Council (ERC) under the European Union's Horizon 2020 research and innovation program (grant agreement No 788489). The authors are also grateful to Business of Finland for the Design Driven Value Chains in the World of Cellulose II. The authors also thank Dr. Mariko Ago, Hannes Orelma and M.Sc Solin Katariina for their support and discussion.

\section{Author contributions}

L.W. prepared and characterized the filaments and wrote the manuscript with the rest of authors. M.L. measured and analyzed the Q.C.M., D.V.S. and A.C.P. performed the WAXS measurements. L.G.G. made the schematic image and measured the filament cross-sectional area via ImageJ. All the other authors discussed the results and reviewed the manuscript.

\section{Competing interests}

The authors declare no competing interests.

\section{Additional information}

Supplementary information is available for this paper at https://doi.org/10.1038/s41598-019-53215-0.

Correspondence and requests for materials should be addressed to O.J.R.

Reprints and permissions information is available at www.nature.com/reprints.

Publisher's note Springer Nature remains neutral with regard to jurisdictional claims in published maps and institutional affiliations.

Open Access This article is licensed under a Creative Commons Attribution 4.0 International License, which permits use, sharing, adaptation, distribution and reproduction in any medium or format, as long as you give appropriate credit to the original author(s) and the source, provide a link to the Creative Commons license, and indicate if changes were made. The images or other third party material in this article are included in the article's Creative Commons license, unless indicated otherwise in a credit line to the material. If material is not included in the article's Creative Commons license and your intended use is not permitted by statutory regulation or exceeds the permitted use, you will need to obtain permission directly from the copyright holder. To view a copy of this license, visit http://creativecommons.org/licenses/by/4.0/.

(C) The Author(s) 2019 